\title{
Signaling in plants by intercellular RNA and protein movement
}

\author{
Xuelin $\mathrm{Wu}^{1}{ }^{1}$ Detlef Weigel, ${ }^{1,2,3}$ and Philip A. Wigge ${ }^{1}$ \\ ${ }^{1}$ Plant Biology Laboratory, The Salk Institute for Biological Studies, La Jolla, California 92037, USA; ${ }^{2}$ Department \\ of Molecular Biology, Max Planck Institute for Developmental Biology, 72076 Tübingen, Germany
}

Plants and animals have had about 1.6 billion years-the time that has passed since they diverged from their last unicellular ancestor-to evolve different mechanisms for solving unique problems of development and intercellular signaling. As an example, plant cells are separated from each other by a substantial extracellular matrix, the cell wall. Although the cell wall is not impervious, it is likely to hinder cell-to-cell communication. Moreover, because plant cells cannot migrate during development, location, instead of lineage, is the primary determinant of cell fate in plants, making communication over both long and short distances essential for the coordination of plant growth. It appears that plants have significantly overcome the downside of having a cell wall by forming channels between cells to allow the transit of signaling and other important molecules. Plants may even be considered as supracellular organisms, in that whole tissues are symplastically connected. The channels that connect plant cells are called plasmodesmata (PD), and their investigation offers tantalizing clues as to how plant cells may use them to communicate with each other and to coordinate development. Although once seen as constricted channels through which only molecules $<1 \mathrm{kD}$ in size could pass (Terry and Robards 1987; Burnell 1988), PD have recently been shown to be far more dynamic and allow passage of both proteins and nucleic acids. Other findings, such as the observation that transcription factors can move between cells, and that RNA movement may be behind a range of long-distance signals in plants, raise further questions regarding a regulatory role of $\mathrm{PD}$ in development. Because of the importance of $\mathrm{PD}$, we first summarize what we know about them, and then go on to discuss intercellular movement of proteins and RNA in general.

\section{Plasmodesmata}

\section{Ultrastructure}

Ultrastructural studies of the PD by transmission electron microscopy (TEM) have shown them to be mem-

${ }^{3}$ Corresponding author.

E-MAIL weigel@weigelworld.org; FAX (858) 558-6379.

Article and publication are at http://www.genesdev.org/cgi/doi/10.1101/ gad.952002. brane-lined pores, with an exterior membrane contributed by the plasma membranes of the two cells connected by the PD, and a central desmotubule, derived from endoplasmic reticulum that is also contiguous between the two cells (Ding 1998). Typically, PD have a small diameter of $\sim 40 \mathrm{~nm}$ (Robards and Lucas 1990; van Bel and van Kesteren 1999), with the central desmotubule being connected to the plasma membrane via spoke-like extensions, resulting in microchannels having an estimated diameter of $\sim 2.5 \mathrm{~nm}$ (see Fig. 1). It is important to bear in mind that these measurements are all based on fixed tissue, and that nothing is known from these observations about the dynamic behavior of PD proteins.

Morphologically, two distinct forms of PD have been recognized. Primary PD are formed at the cell plate, a plant-typical structure that consists of the incipient plasma membrane and cell wall synthesized during cytokinesis. Secondary PD, in contrast, are formed between existing cell walls. Both forms of PD can be either single-channels or branched. It is not known whether these different forms of PD have distinct functions.

\section{Proteins of the PD}

A complete understanding of how the PD function to control movement of molecules between plant cells is dependent on identifying the proteins of which they are composed. Genetic screens to identify mutants defective in intercellular movement are hindered by the fact that PD components are probably essential for viability. Because it is questionable whether one can recover viable mutants that are seriously defective in the structure or function of PD, it will probably be essential to study mutants at the embryo stage of development. One such screen is briefly mentioned in a recent review (Zambryski and Crawford 2000). It has led to the identification of an embryonic lethal mutant, ise-1, in which tracer molecules of up to $11 \mathrm{kD}$ can easily move between cells, which is a substantial increase over the wild-type size exclusion limit of $<3 \mathrm{kD}$. The disrupted gene is a promising candidate for a protein that regulates the aperture of PD.

A complementary approach to the genetic dissection of PD function is to biochemically purify these organ- 
Wu et al.

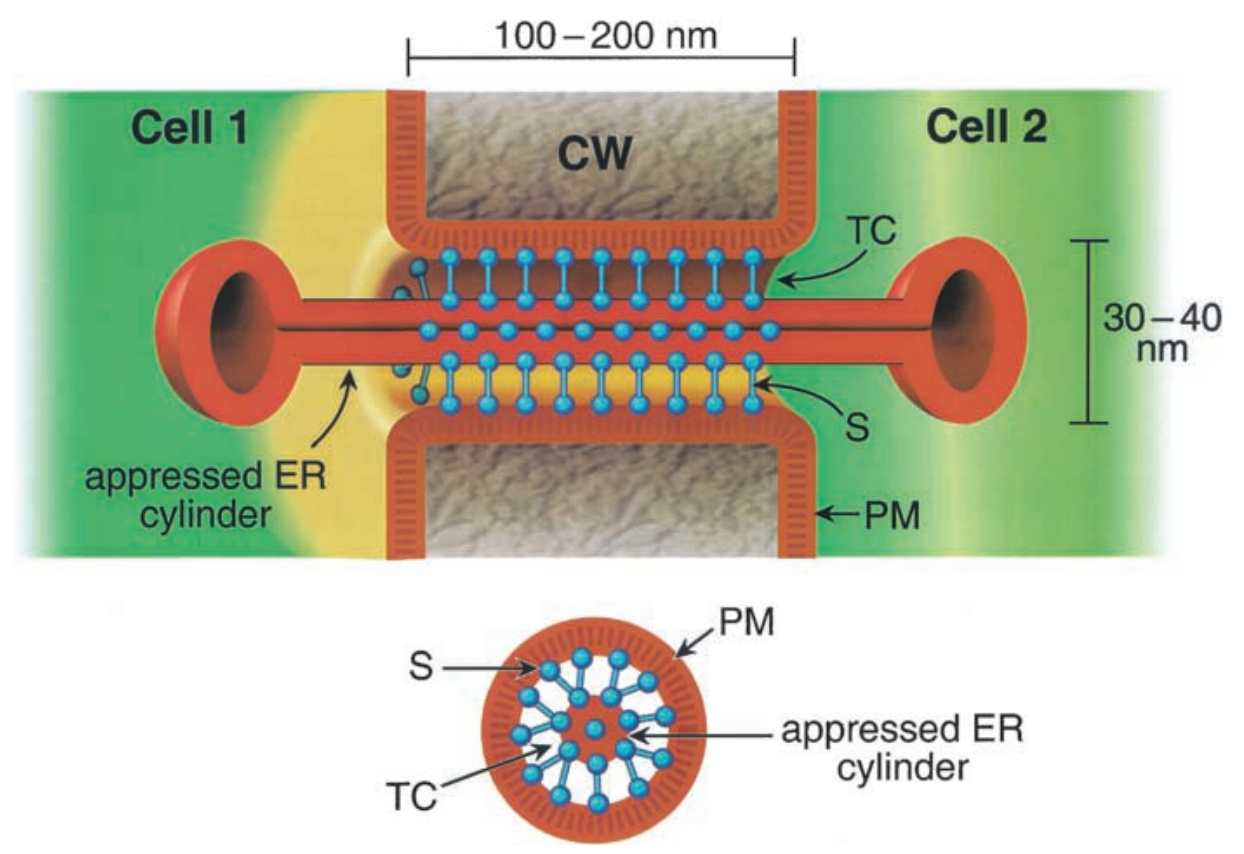

Figure 1. A longitudinal schematic cross section through a PD. Molecules are thought to be transported through the transport channels (TC) between the appressed ER and plasma membrane (PM). Spoke-like structures (S) connect the appressed ER to the PM. Below is a transverse cross section of the same structure. Adapted from Ding (1998).

elles from cell walls and then to identify the PD constituents directly. Although potentially powerful, this approach has so far been hampered by the small amount of protein present and the difficulty in extracting intact PD from the cell wall without subcellular contaminants (Epel 1994; Epel et al. 1995). Nevertheless, proteins purified from cell walls have been used to raise antibodies, which by immunoelectron microscopy have been shown to recognize epitopes at the PD. However, none of the genes that encode the proteins recognized by these antibodies have been isolated (Epel 1994; Waigmann et al. 1997).

By serendipity, at least two plant proteins have definitively been identified as residing at the PD. A plantspecific form of the molecular motor myosin from Arabidopsis thaliana (myosin VIII) has been shown to be present in the PD of the post-cytokinetic cell wall (Reichelt et al. 1999). The authors propose that myosin VIII plays a role in maturation of the cell plate and the reestablishment of actin cables between cells to allow intercellular communication. The same group has also found by immunoelectron microscopy that the multifunctional calcium-sequestering protein calreticulin is enriched in ER domains associated with the PD of maize (Baluska et al. 1999). Because myosin function is regulated by calcium binding, the authors have speculated that calreticulin regulates myosin VIII and thereby provides a $\mathrm{Ca}^{2+}$-dependent gating mechanism for $\mathrm{PD}$. Other cytoskeletal antigens have been identified as potential PD components by microscopy as well, including actin and myosin in the alga Chara corallina (Blackman and Overall 1998), as well as actin-like and myosin-like molecules in diverse plant species (White et al. 1994; Radford and White 1998).

\section{Size exclusion limits of plasmodesmata}

The narrow aperture of the PD seen in the TEM suggested that PD would only allow the passage of very small molecules. Injection studies with fluorescently labeled dextrans generally supported the view of the PD as static channels through which only molecules of $<1 \mathrm{kD}$ could diffuse (Tucker 1982; Goodwin 1983; Erwee and Goodwin 1985; Terry and Robards 1987; Burnell 1988). Additionally, there appear to be boundaries that limit the diffusion even of small dyes, thereby dividing tissues into so-called symplasmic domains. Interestingly, the extent of symplasmic domains as determined by injection of fluorescent dyes is under developmental regulation, even though the biological significance is unknown (Rinne and van der Schoot 1998; Gisel et al 1999).

The dogma that PD allow only the diffusion of small molecules has been challenged from several sides during the past few years, with data showing that the PD are dynamic in nature and that they allow the nonspecific trafficking of numerous proteins. Crawford and Zambryski (2000) used a noninvasive transfection system to show that a red-shifted version of GFP $(27 \mathrm{kD})$ moved readily in tobacco plant leaves, and they even found limited movement of 2xGFP (54 kD). In these and other studies, the size exclusion limit (SEL) has been shown to be closely related to the developmental state of the tissue. When tobacco leaves mature and change from being net consumers of carbon (sink tissue) to being carbon exporters (source tissue), there is a dramatic decrease in the SEL (Oparka et al. 1999). Whereas molecules of up to $50 \mathrm{kD}$ may move freely in sink tissue, movement is greatly reduced in the source tissue. This change in SEL 
is accompanied by a change of PD morphology from simple to branched (Oparka et al. 1999). In a complementary study, GFP was expressed under a promoter specific for so-called companion cells, which line the phloem, the part of the vasculature that transports assimilates. In these transgenic plants, GFP could move over long distances through the phloem into leaves and other sink tissues (Imlau et al. 1999).

\section{Plasmodesmata, viral movement proteins,} and the plant cytoskeleton

A major contribution to our understanding of PD function comes from the investigation of plant viruses (Lazarowitz 1999). For viruses to successfully infect plants, they must be able to spread from cell to cell, a process that is greatly restricted by the presence of cell walls. To bypass these formidable barriers, viruses have evolved highly efficient mechanisms that exploit the cytoskeleton within plant cells, and that allow them to traffic in a rapid targeted fashion throughout the plant. Many plant viruses encode movement proteins that actively target the PD and that are essential for viral infectivity. In the absence of these proteins, viruses will replicate and encapsidate their genomes, but they are unable to spread from cell to cell. Movement proteins have many interesting properties, and they have become essential tools for studying intercellular transport. Plants contain endogenous proteins that are antigenically related to viral movement proteins and that may share similar functions (Xoconostle-Cázares et al. 1999).

The best studied viral protein is the $30-\mathrm{kD}$ movement protein from tobacco mosaic virus (TMV MP30). Apart from overexpression studies, which first showed that MP30 can increase the SEL of PD (Wolf et al. 1989), the analysis of GFP fusions by light microscopy has revealed a large amount of information about movement protein function. The tagged proteins are seen to interact with the ER, the actin and microtubule cytoskeleton, as well as with the PD themselves (Heinlein et al. 1995; McLean et al. 1995; Mas and Beachy 1999, 2000; Boyko et al. 2000b). Consistent with the apparent microtubule association, MP30 has been found to have a conserved motif for microtubule binding (Boyko et al. 2000a). It has been proposed that the binding of MP30 to the sides of microtubules enables it to be actively transported between cells. Consistent with this hypothesis, disruption of the interaction between MP30 and the cytoskeleton prevents both viral movement and infectivity (Boyko et al. 2000a). The association of MP30 with the ER is likely related to the fact that viral replication occurs on the ER (Mas and Beachy 1999). It is thought that, in some cases, the viral movement protein associates with viral RNA, and that this complex is transported along the cytoskeleton to the $\mathrm{PD}$, through which the virus is delivered to adjacent cells. Other studies indicate that movement proteins not only are able to target PD, but also actively dilate the PD, enabling the increased movement of other proteins in infected cells. It has thus been proposed that PD may be considered as having three states: closed, open, and dilated (Dorokhov et al. 1999; Crawford and Zambryski 2000).
Based on the argument that viral movement through PD must require plant host factors, several groups have taken biochemical and reverse genetic approaches to dissect viral movement. These efforts indicate the involvement of at least two cell wall-associated enzymes in viral movement and thus presumably PD function. Two independent screens led to the identification of pectin methylesterase, an enzyme that modifies the pectin in cell walls, as a protein that directly interacts with TMV MP30 in vitro (Chen et al. 2000). In another study, it was found that reduction of $\beta$-1,3-glucanase activity in transgenic plants both decreased the SEL and slowed intercellular viral movement (Iglesias and Meins 2000). The mechanisms by which these host factors may affect PD function need to be further clarified.

\section{Movement of RNA and proteins in plants}

Although much of our knowledge of PD and the movement of macromolecules has come from the investigation of plant-virus interactions, this should not overshadow the importance of PD for endogenous plant processes such as signal relay, defense, or transport of nutrients. Most of the early studies on PD function were carried out using microinjection or biolistic bombardment to deliver tracer molecules, and the results from these reports have been recently reviewed in detail (Crawford and Zambryski 2000). Here we focus on movement observed using genetic chimeras, including grafts and periclinal chimeras, and tissue-specific transgenic expression of signaling molecules (Fig. 2).

\section{Long-distance movement along the phloem}

Long-distance transport of a variety of molecules, including but not limited to water, nutrients, hormones, and other signals, is essential for plant growth. Long-distance transport relies on the plant vascular system, which includes two tissues, the xylem and the phloem. The xylem mainly consists of files of dead cells, and the flow within it is driven by a tension gradient. On the other hand, the sieve elements of the phloem are formed by files of living, but enucleate, cells. The sieve elements and the surrounding companion cells descend from the same mother cells, and they are connected by a large number of plasmodesmata, which have a larger SEL compared to the ones found in mature leaves (Imlau et al. 1999|. Because the sieve elements have lost most of their organelles, proteins and mRNAs required for their function are produced in their immediate neighbors, the companion cells, then transported into the sieve elements. The clearest evidence for an involvement of PD in this process comes from studies of the sucrose transporter SUT1 (Kühn et al. 1997). Both SUT1 mRNA and protein are detected in sieve elements by in situ localization, with preferential association of mRNA with the $\mathrm{PD}$. That the mRNA is produced in the companion cells was shown directly by inhibiting its synthesis in these cells using an antisense construct driven by a companion-cell-specific promoter (Kühn et al. 1997). The role of 
Wu et al.

A

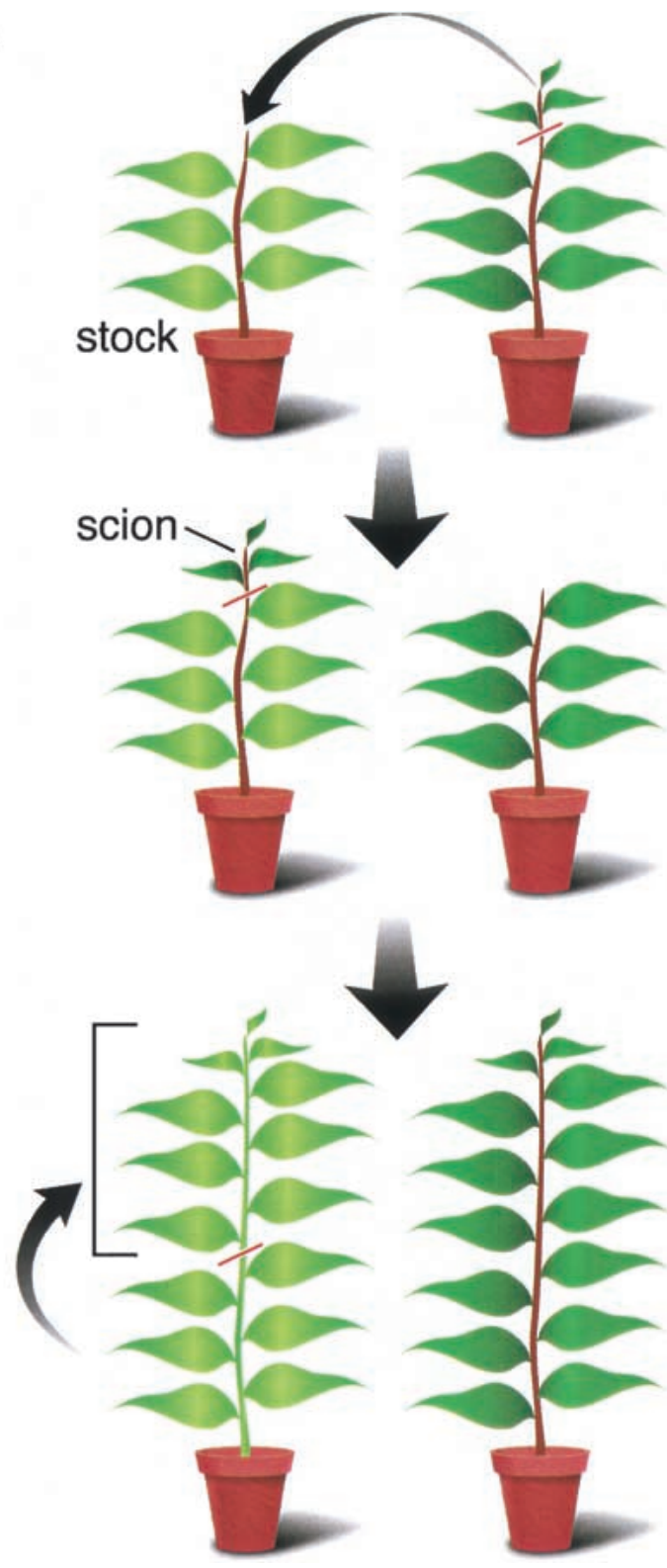

B
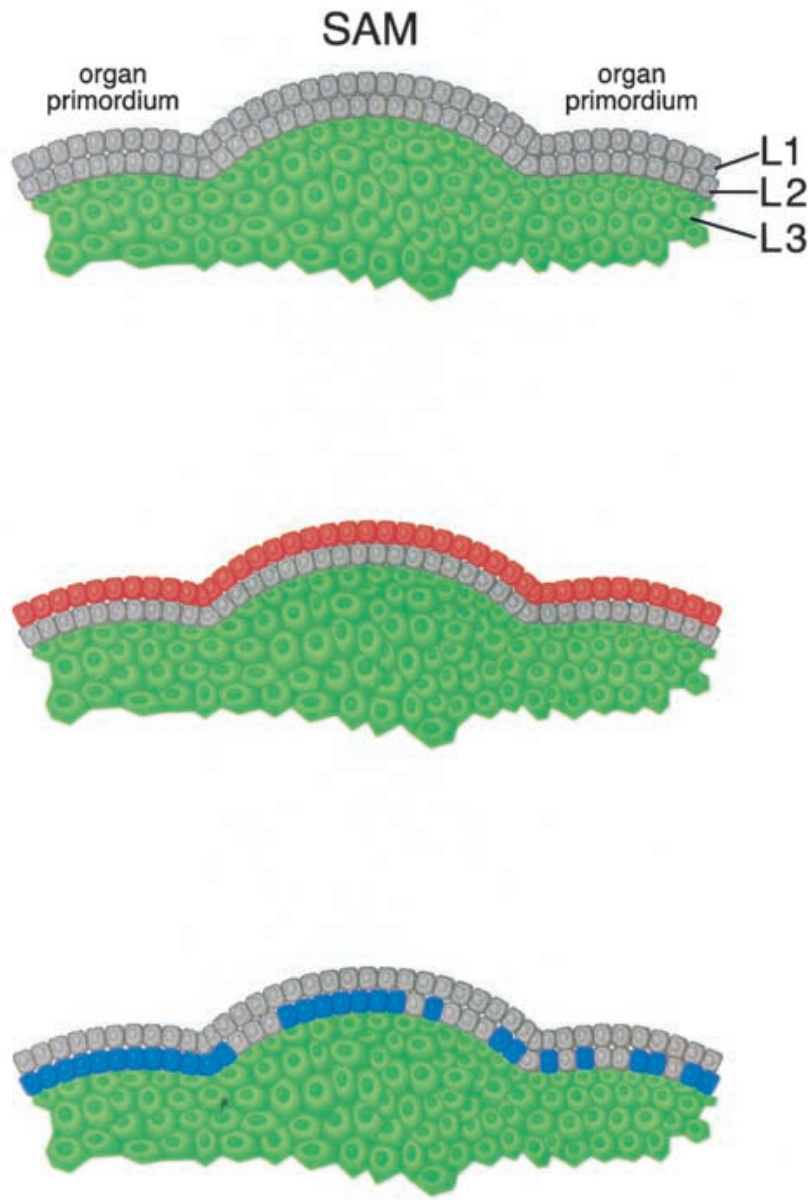

Figure 2. Diagrams of different methods to generate genetic chimeras. (A) In grafting experiments, a scion (dark green) is grafted onto a stock (light green) that is genetically different, for example, because it carries a transgene. If the phenotype is graft-transmissible, the scion will develop the same phenotype as the stock owing to movement of the signal through the phloem. $(B, t o p)$ Cross section of a shoot apex, showing the three tissue layers. The shoot apical meristem (SAM) is at the center, with emerging organ primordia on both sides. (Middle) Localized ectopic expression can be driven by an epidermis-specific promoter in L1 only. (Bottom) Induced genetic recombination can result in clones of marked cells in L2 with different genetic composition.

PD between companion cells and sieve elements in gating the up-loading and unloading of these and other molecules into the phloem has been discussed in detail by Ruiz-Medrano et al. (2001).

In the past few years, long-distance movement of RNA has caught much attention. Using grafting experiments with transgenic and wild-type plants, Palauqui and Vaucheret (1998) were the first to show that posttranscriptional silencing, a syndrome that includes RNA interference (RNAi), can spread to cells that do not contain the causal transgene. The signal consists most likely of small interfering RNAs (siRNAs; Elbashir et al. 2001) that are transported through the phloem, and leads to the silencing of genes bearing sequence homology to the RNA molecules (e.g., Hamilton and Baulcombe 1999; Di Serio et al. 2001; Hutvagner et al. 2001; Matzke et al. 2001). This mechanism provides an important line of defense against a number of viruses, many of which have in turn developed strategies to render this mechanism ineffective (for reviews, see Fagard and Vaucheret 2000; Meins 2000; Vance and Vaucheret 2001). Apart from these small RNAs, several mRNAs have been isolated from phloem sap of pumpkin and shown by grafting experiments to traffic for long distances via the phloem. Some of these RNAs encode proteins that are related to viral movement proteins, but others encode proteins 
with similarity to developmental regulators (Ruiz-Medrano et al. 1999; Xoconostle-Cázares et al. 1999). In another elegant grafting experiment, the effects of longdistance mRNA movement have recently been shown. A naturally occurring mutation in tomato, Mouse ear $(\mathrm{Me})$, is the result of a gene fusion in which regulatory sequences of the PYRO-PHOSPHATE-DEPENDENT PHOSPHO-FRUCTOKINASE (PFP) gene cause highlevel expression of the homeobox gene LeT6, resulting in altered leaf morphology (Chen et al. 1997). Kim et al. (2001) showed that the Me mRNA can move from mutant stocks into wild-type scions, with the consequence that genetically wild-type scions show the $M e$ phenotype. This observation strongly supports the assertion that long-distance movement of mRNAs is used as a developmental signal.

\section{Short-distance movement of transcription factors and their sense RNAs}

Plant growth differs from that of animals in that most organs originate postembryonically from meristems, which are groups of undifferentiated cells that are set aside during embryogenesis. The aerial parts of the plants are generated by the shoot apical meristem (SAM), which consists of three tissue layers: the outer most layer, L1; the subsurface layer, L2; and the inner layer, L3. These three layers produce the epidermis, subepidermis, and inner tissues such as the vasculature, respectively. In dicotyledonous plants, cells in the L1 and L2 divide almost exclusively in a single plane, with the result that cells in each layer are normally clonally related (see Fig. 2; Sussex 1989). Cells within the same layer are therefore connected mostly via primary PD, and cells from adjacent layers via secondary PD (Ding 1998). Because all three layers contribute to cell proliferation and organ differentiation, extensive intercellular communication is required to coordinate their growth. The existence of cross talk between layers has been shown in several plant species using periclinal chimeras, in which neighboring layers have different genetic composition (Szymkowiak and Sussex 1992, 1993).

Among the genes that have been shown to have noncell-autonomous functions are several transcription factors controlling flower development /Carpenter and Coen 1995; Hantke et al. 1995; Bouhidel and Irish 1996; Perbal et al. 1996; Sieburth et al. 1998; Sessions et al. 2000; Jenik and Irish 2001). Initially, it was assumed that their non-cell-autonomous effects were carried out by downstream effectors, such as secreted molecules, because transcription factors were not known to be secreted or move otherwise between adjacent cells. It therefore came as a surprise when Jackson et al. (1994) reported that the homeobox-containing transcription factor KNOTTED 1 (KN1) can be detected in the L1 of the maize SAM, even though its RNA is limited to the L2 and L3. The authors insightfully speculated that this discrepancy was caused by KN1 movement, a hypothesis supported by subsequent experiments, in which fluorescently labeled KN1 was injected into tobacco leaf cells
(Lucas et al. 1995). In this experimental setup, KN1 appeared to generally increase the SEL of PD, and to even effect specific movement of its own sense RNA. Interestingly, the domain required for KN1 movement in tobacco leaves was pinpointed to a potential nuclear localization signal in the $\mathrm{N}$-terminal part of the homeodomain. Unfortunately, it has not yet been possible to study the effects of KN1 movement within meristem, although KN1 is known to have nonautonomous effects when expressed ectopically.

Soon after this first example of transcription factor movement, Perbal et al. (1996) found that the Antirrhinum MADS domain protein DEFICIENS (DEF) can move within developing flowers. Using genetic chimera, they showed that DEF can move from the L2 into the L1, but not in the other direction. A third transcription factor shown to move within floral meristems is LEAFY (LFY) in Arabidopsis (Sessions et al. 2000). The most dramatic results were seen when $L F Y$ was expressed from the epidermis-specific $M L 1$ promoter: Although the RNA was, as expected, restricted to the L1, LFY protein was found in a gradient that extended into several interior cell layers. The functionality of trafficked LFY protein was shown both by complete rescue of the mutant phenotype, and by the ability of LFY to activate a direct target gene in interior layers.

A caveat of the DEF and LFY studies was that the biological significance of their movement was unclear, because there are no striking differences in their RNA and protein patterns in wild-type plants, although it has been speculated that LFY movement presents a redundant mechanism to ensure that all three tissue layers in the meristem coordinately adopt floral fate. A more recent publication, however, no longer leaves any doubt as to the significance of transcription factor movement in plant development (Nakajima et al. 2001). Similarly to the shoot, the root is formed by a meristem comprising the root initials. There are distinct initials that give rise to several radially organized layers in the mature root, including from the center to the periphery, the stele, the endodermis, the cortex, and the epidermis. The SHORT ROOT (SHR) gene, which encodes a member of the GRAS family of transcription factors, is required for the formation of the single-cell-layered endodermis, which descends from the same mother cells as the cortex layer. Plants lacking SHR activity fail to develop the endodermis layer (Benfey et al. 1993; Helariutta et al. 2000). In situ hybridization had revealed that $S H R$ RNA is expressed only in the stele (Helariutta et al. 2000), but subsequent studies using both GFP fusions and immunohistochemistry showed that the protein product is found in both the stele and the adjacent endodermis (Nakajima et al. 2001). Thus, in the wild-type root, SHR protein moves one cell away from its source of expression to the cell layer where its function is required. Using an SHR-GFP fusion protein expressed from its own promoter, Nakajima et al. (2001) showed that SHR is both nuclear and cytoplasmic in the stele, but strictly nuclear in the endodermis. In a beautiful extension of this work, the authors also asked whether there might be a reason for $S H R$ 
RNA not being made in endodermal cells in the first place, by examining plants in which $S H R$ is expressed under the control of the endodermis-specific SCARECROW (SCR) promoter. In these plants, additional endodermal layers are generated, indicating that SHR transcription in the endodermis is detrimental. There are several possible explanations for this observation: A trivial explanation would be that increasing the amount of SHR in the endodermis by expressing it there directly allows it to escape to adjacent cells. One can think of several more elaborate scenarios, involving, for example, modifications during movement.

\section{Mechanisms of transcription factor movement}

Contrary to the common belief that transcription factors should be transported into nuclei as soon as they are made, several transcription factors in plants have been shown to be able to move in developing tissues. How do these proteins go across cellular boundaries? PD seem to be the most suitable answer. The first evidence came from the observation that injected KN1 can change the SEL of tobacco leaf mesophyll cells (Lucas et al. 1995). An interaction with the PD is further supported by the finding that a KN1 peptide can interfere with KN1's ability to dilate the PD and to move its mRNA into neighboring cells (Kragler et al. 2000). Also, the fact that cells within a layer are typically connected by primary PD but cells in adjacent layers are typically connected by secondary PD suggests a functional basis for the observation that DEF can only move from L2 into L1, but not within a layer (Perbal et al. 1996; Efremova et al. 2001). Nevertheless, the mechanisms behind the movement of these proteins remain unknown, and it is noteworthy that several animal transcription factors of the homeodomain family can traffic between cells in culture using unconventional secretion and uptake mechanisms (Joliot et al. 1991; Maizel et al. 1999).

Meristems are the youngest tissues found in a plant, and the PD found there are thought to have the largest size exclusion limit (Zambryski and Crawford 2000). So far, most examples of endogenous transcription factor movement are from meristematic tissues. However, not all transcription factors with non-cell-autonomous effects move in the meristem. The latter group includes the Arabidopsis MADS domain protein APETALA3 (AP3), the ortholog of DEF, and its heterodimerization partner PISTILLATA (PI), both of which are similar in size to GFP (Jenik and Irish 2001).

Although it is reassuring that not all transcription factors move freely in the plant, these observations indicate that there must be active mechanisms that regulate transcription factor movement. So far, it has been largely assumed that nonmovement is the default, and that movement is predominantly active. An alternative hypothesis would be that movement by diffusion is a default pathway. Movement by diffusion would be consistent with the graded distribution of LFY protein observed in plants that expressed LFY RNA only in the L1 (Sessions et al. 2000). We note that even if movement is at least partially by diffusion, this would not diminish the biological significance of intercellular protein trafficking.

In a scenario where diffusion is an important mechanism for intercellular protein movement, retention of signaling molecules and transcription factors in their source tissue may be as important as active transport. Retention could be achieved by targeting proteins to specific cellular compartments /Crawford and Zambryski 2000), or by complexing a protein with other factors. The latter scenario could apply in the case of AP3 and PI, for they are known to form stable complexes with other MADS proteins (McGonigle et al. 1996; Riechmann et al. 1996; Egea-Cortines et al. 1999; Honma and Goto 2001). In the case of SHR, the hypothetical interaction partner(s) might only be present in the endodermis, and effectively trap SHR (although one would have to postulate that this trapping mechanism is somehow defeated when the amount and/or timing of SHR production is changed in SCR::SHR transgenic lines (Nakajima et al. 2001).

\section{Summary and perspectives}

Although once regarded as static pores with a very restricted size exclusion limit, PD have been shown to be dynamic organelles, capable of allowing the passage of a wide variety of macromolecules. Through the use of fluorescently tagged proteins, it has become evident that there are two mechanisms for transport: targeted movement, in which transport occurs systematically across many cell layers (an example being that of viral movement proteins), and nontargeted movement (which might be the predominant mode of transcription factor movement in meristems). Correspondingly, it has been suggested that the PD exist in three different states: closed, open (permitting nontargeted movement), and dilated (required for targeted movement).

A key question that remains is what role, if any, PD have in regulating movement of molecules between cells. Although PD have been shown to close in response to physiological stress and with age, it is possible that the cell-to-cell passage of many proteins is the default in young, growing tissue. Presumably, proteins whose activity must be restricted to a particular region are specifically retained, with an example being floral homeotic proteins like AP3. There is so far no evidence that PD control movement of transcription factors, but trafficking of developmental regulators may be regulated at several levels, for example, via intracellular localization, binding partners, or posttranslational modification. All these mechanisms may be largely independent of the PD. Interestingly, systemic expression of viral movement proteins in transgenic plants, which have been reported to dilate the PD, has often no obvious phenotypic or developmental consequences (e.g., Wolf et al. 1989; Deom et al. 1990), suggesting that even dilated PD do not permit the free movement of all proteins.

Finally, although the last few years have seen exciting discoveries in the field of intercellular movement of plant macromolecules, one should not forget that plant 
cells are perfectly able to communicate using secreted ligands and extracellular receptors (Clark 2001). The relative contribution of this type of classic signaling and of unconventional signaling via movement through PD to intercellular communication is likely to provide interesting discussions for years to come.

\section{Acknowledgments}

We apologize to our colleagues whose work has not been cited in full because of space constraints. We thank two anonymous reviewers for their helpful comments in an area in which we are novices. Work on protein movement in our laboratory is supported by fellowships from LSRF/DOE to X.W. and Wellcome Trust to P.A.W., and a grant from NIH to D.W. D.W. is a Director of the Max Planck Institute.

\section{References}

Baluska, F., Samaj, J., Napier, R., and Volkmann, D. 1999. Maize calreticulin localizes preferentially to plasmodesmata in root apex. Plant J. 19: 481-488.

Benfey, P.N., Linstead, P.J., Roberts, K., Schiefelbein, J.W., Hauser, M.T., and Aeschbacher, R.A. 1993. Root development in Arabidopsis: Four mutants with dramatically altered root morphogenesis. Development 119: 57-70.

Blackman, L.M. and Overall, R.L. 1998. Immunolocalisation of the cytoskeleton to plasmodesmata in Chara corallina. Plant I. 14: 733-741.

Bouhidel, K. and Irish, V.F. 1996. Cellular interactions mediated by the homeotic PISTILLATA gene determine cell fate in the Arabidopsis flower. Dev. Biol. 174: 22-31.

Boyko, V., Ferralli, J., Ashby, J., Schellenbaum, P., and Heinlein, M. 2000a. Function of microtubules in intercellular transport of plant virus RNA. Nat. Cell Biol. 2: 826-832.

Boyko, V., Ferralli, J., and Heinlein, M. 2000b. Cell-to-cell movement of TMV RNA is temperature-dependent and corresponds to the association of movement protein with microtubules. Plant J. 22: 315-325.

Burnell, J.N. 1988. An enzymatic method for measuring the molecular weight exclusion limit of plasmodesmata of bundle sheath cells of C4 plants. J. Exp. Bot. 39: 1575-1580.

Carpenter, R. and Coen, E.S. 1995. Transposon induced chimeras show that floricaula, a meristem identity gene, acts nonautonomously between cell layers. Development 121: 19-26.

Chen, J.J., Janssen, B.J., Williams, A., and Sinha, N. 1997. A gene fusion at a homeobox locus: Alterations in leaf shape and implications for morphological evolution. Plant Cell 9: 1289-1304.

Chen, M.H., Sheng, J., Hind, G., Handa, A.K., and Citovsky, V. 2000. Interaction between the tobacco mosaic virus movement protein and host cell pectin methylesterases is required for viral cell-to-cell movement. EMBO J. 19: 913-920.

Clark, S.E. 2001. Cell signalling at the shoot meristem. Nat. Rev. Mol. Cell Biol. 2: 276-284.

Crawford, K.M. and Zambryski, P.C. 2000. Subcellular localization determines the availability of non-targeted proteins to plasmodesmatal transport. Curr. Biol. 10: 1032-1040.

2. 2001. Non-targeted and targeted protein movement through plasmodesmata in leaves in different developmental and physiological states. Plant Physiol. 125: 1802-1812.

Deom, C.M., Schubert, K.R., Wolf, S., Holt, C.A., Lucas, W.J., and Beachy, R.N. 1990. Molecular characterization and biological function of the movement protein of tobacco mosaic virus in transgenic plants. Proc. Natl. Acad. Sci. 87: 3284-3288.

Ding, B. 1998. Intercellular protein trafficking through plasmodesmata. Plant Mol. Biol. 38: 279-310.

Di Serio, F., Schob, H., Iglesias, A., Tarina, C., Bouldoires, E., and Meins, F., Jr. 2001. Sense- and antisense-mediated gene silencing in tobacco is inhibited by the same viral suppressors and is associated with accumulation of small RNAs. Proc. Nat1. Acad. Sci. 98: 6506-6510.

Dorokhov, Y.L., Makinen, K., Frolova, O.Y., Merits, A., Saarinen, J., Kalkkinen, N., Atabekov, J.G., and Saarma, M. 1999. A novel function for a ubiquitous plant enzyme pectin methylesterase: The host-cell receptor for the tobacco mosaic virus movement protein. FEBS Lett. 461: 223-228.

Efremova, N., Perbal, M.C., Yephremov, A., Hofmann, W.A., Saedler, H., and Schwarz-Sommer, Z. 2001. Epidermal control of floral organ identity by class B homeotic genes in Antirrhinum and Arabidopsis. Development 128: 2661-2671.

Egea-Cortines, M., Saedler, H., and Sommer, H. 1999. Ternary complex formation between the MADS-box proteins SQUAMOSA, DEFICIENS and GLOBOSA is involved in the control of floral architecture in Antirrhinum majus. EMBO $\mathrm{J}$. 18: 5370-5379.

Elbashir, S.M., Harborth, J., Lendeckel, W., Yalcin, A., Weber, K., and Tuschl, T. 2001. Duplexes of 21-nucleotide RNAs mediate RNA interference in cultured mammalian cells. $\mathrm{Na}$ ture 411: 494-498.

Epel, B.L. 1994. Plasmodesmata: Composition, structure and trafficking. Plant Mol. Biol. 26: 1343-1356.

Epel, B.L., Kuchuck, B., Kotlizky, G., Shurtz, S., Erlanger, M., and Yahalom, A. 1995. Isolation and characterization of plasmodesmata. Methods Cell Biol. 50: 237-253.

Erwee, M.G. and Goodwin, P.B. 1985. Symplastic domains in extrastelar tissues of Egeria densa Planch. Planta 163: 9-19.

Fagard, M. and Vaucheret, H. 2000. Systemic silencing signal(s). Plant Mol. Biol. 43: 285-293.

Gisel, A., Barella, S., Hempel, F., and Zambryski, P. 1999. Temporal and spatial regulation of symplastic trafficking during development in Arabidopsis thaliana apices. Development 126: $1879-1889$

Goodwin, P.B. 1983. Molecular size limit for movement in the symplast of the Elodea leaf. Planta 157: 124-130.

Hamilton, A.J. and Baulcombe, D.C. 1999. A species of small antisense RNA in posttranscriptional gene silencing in plants. Science 286: 950-952.

Hantke, S.S., Carpenter, R., and Coen, E.S. 1995. Expression of floricaula in single cell layers of periclinal chimeras activates downstream homeotic genes in all layers of floral meristems. Development 121: 27-35.

Heinlein, M., Epel, B.L., Padgett, H.S., and Beachy, R.N. 1995. Interaction of tobamovirus movement proteins with the plant cytoskeleton. Science 270: 1983-1985.

Helariutta, Y., Fukaki, H., Wysocka-Diller, J., Nakajima, K., Jung, J., Sena, G., Hauser, M.T., and Benfey, P.N. 2000. The SHORT-ROOT gene controls radial patterning of the Arabidopsis root through radial signaling. Cell 101: 555-567.

Honma, T. and Goto, K. 2001. Complexes of MADS-box proteins are sufficient to convert leaves into floral organs. $\mathrm{Na}$ ture 409: 525-529.

Hutvagner, G., McLachlan, J., Pasquinelli, A.E., Balint, E., Tuschl, T., and Zamore, P.D. 2001. A cellular function for the RNA-interference enzyme Dicer in the maturation of the let-7 small temporal RNA. Science 293: 834-838.

Iglesias, V.A. and Meins, F., Jr. 2000. Movement of plant viruses is delayed in a $\beta$-1,3-glucanase-deficient mutant showing a reduced plasmodesmatal size exclusion limit and enhanced callose deposition. Plant J. 21: 157-166. 
Imlau, A., Truernit, E., and Sauer, N. 1999. Cell-to-cell and long-distance trafficking of the green fluorescent protein in the phloem and symplastic unloading of the protein into sink tissues. Plant Cell 11: 309-322.

Jackson, D., Veit, B., and Hake, S. 1994. Expression of maize KNOTTED1 related homeobox genes in the shoot apical meristem predicts patterns of morphogenesis in the vegetative shoot. Development 120: 405-413.

Jenik, P. and Irish, V. 2001. The Arabidopsis floral homeotic gene APETALA3 differentially regulates intercellular signaling required for petal and stamen development. Development 128: 13-23.

Joliot, A., Pernelle, C., Deagostini-Bazin, H., and Prochiantz, A. 1991. Antennapedia homeobox peptide regulates neural morphogenesis. Proc. Natl. Acad. Sci. 88: 1864-1868.

Kim, M., Canio, W., Kessler, S., and Sinha, N. 2001. Developmental changes due to long-distance movement of a homeobox fusion transcript in tomato. Science 293: 287-289.

Kragler, F., Monzer, J., Xoconostle-Cázares, B., and Lucas, W.J. 2000. Peptide antagonists of the plasmodesmal macromolecular trafficking pathway. EMBO J. 19: 2856-2868.

Kühn, C., Franceschi, V.R., Schulz, A., Lemoine, R., and Frommer, W.B. 1997. Macromolecular trafficking indicated by localization and turnover of sucrose transporters in enucleate sieve elements. Science 275: 1298-1300.

Lazarowitz, S.G. 1999. Probing plant cell structure and function with viral movement proteins. Curr. Opin. Plant Biol. 2: 332-338.

Lucas, W.J., Bouche-Pillon, S., Jackson, D.P., Nguyen, L., Baker, L., Ding, B., and Hake, S. 1995. Selective trafficking of KNOTTED1 homeodomain protein and its mRNA through plasmodesmata. Science 270: 1980-1983.

Maizel, A., Bensaude, O., Prochiantz, A., and Joliot, A. 1999. A short region of its homeodomain is necessary for engrailed nuclear export and secretion. Development 126: 3183-3190.

Mas, P. and Beachy, R.N. 1999. Replication of tobacco mosaic virus on endoplasmic reticulum and role of the cytoskeleton and virus movement protein in intracellular distribution of viral RNA. J. Cell Biol. 147: 945-958.

2000. Role of microtubules in the intracellular distribution of tobacco mosaic virus movement protein. Proc. Nat1. Acad. Sci. 97: 12345-12349.

Matzke, M., Matzke, A.J.M., and Kooter, J.M. 2001. RNA: Guiding gene silencing. Science 293: 1080-1083.

McGonigle, B., Bouhidel, K., and Irish, V.F. 1996. Nuclear localization of the Arabidopsis APETALA3 and PISTILLATA homeotic gene products depends on their simultaneous expression. Genes \& Dev. 10: 1812-1821.

McLean, B.G., Zupan, J., and Zambryski, P.C. 1995. Tobacco mosaic virus movement protein associates with the cytoskeleton in tobacco cells. Plant Cell 7: 2101-2114.

Meins, Jr., F. 2000. RNA degradation and models for post-transcriptional gene-silencing. Plant Mol. Biol. 43: 261-273.

Nakajima, K., Sena, G., Nawy, T., and Benfey, P.N. 2001. Intercellular movement of the putative transcription factor SHR in root patterning. Nature 413: 307-311.

Oparka, K.J., Roberts, A.G., Boevink, P., Santa Cruz, S., Roberts, I., Pradel, K.S., Imlau, A., Kotlizky, G., Sauer, N., and Epel, B. 1999. Simple, but not branched, plasmodesmata allow the nonspecific trafficking of proteins in developing tobacco leaves. Cell 97: 743-754.

Palauqui, J.-C. and Vaucheret, H. 1998. Transgenes are dispensable for the RNA degradation step of cosuppression. Proc. Nat1. Acad. Sci. 95: 9675-9680.

Perbal, M.C., Haughn, G., Saedler, H., and Schwarz-Sommer, Z. 1996. Non-cell-autonomous function of the Antirrhinum floral homeotic proteins DEFICIENS and GLOBOSA is ex- erted by their polar cell-to-cell trafficking. Development 122: 3433-3441.

Radford, J.E. and White, R.G. 1998. Localization of a myosinlike protein to plasmodesmata. Plant J. 14: 743-750.

Reichelt, S., Knight, A.E., Hodge, T.P., Baluska, F., Samaj, J., Volkmann, D., and Kendrick-Jones, J. 1999. Characterization of the unconventional myosin VIII in plant cells and its localization at the post-cytokinetic cell wall. Plant J. 19: 555567.

Riechmann, J.L., Krizek, B.A., and Meyerowitz, E.M. 1996. Dimerization specificity of Arabidopsis MADS domain homeotic proteins APETALA1, APETALA3, PISTILLATA, and AGAMOUS. Proc. Natl. Acad. Sci. 93: 4793-4798.

Rinne, P. and van der Schoot, C. 1998. Symplasmic fields in the tunica of the shoot apical meristem coordinate morphogenetic events. Development 125: 1477-1485.

Robards, A.W. and Lucas, W.J. 1990. Plasmodesmata. Annu. Rev. Plant Physiol. Plant Mol. Biol. 41: 369-419.

Ruiz-Medrano, R., Xoconostle-Cázares, B., and Lucas, W.J. 1999. Phloem long-distance transport of CmNACP mRNA: Implications for supracellular regulation in plants. Development 126: 4405-4419.

- 2001. The phloem as a conduit for inter-organ communication. Curr. Opin. Plant Biol. 4: 202-209.

Sessions, A., Yanofsky, M.F., and Weigel, D. 2000. Cell-cell signaling and movement by the floral transcription factors LEAFY and APETALA1. Science 289: 779-781.

Sieburth, L.E., Drews, G.N., and Meyerowitz, E.M. 1998. Nonautonomy of AGAMOUS function in flower development: Use of a Cre/loxP method for mosaic analysis in Arabidopsis. Development 125: 4303-4312.

Sussex, I.M. 1989. Developmental programming of the shoot meristem. Cell 56: 225-229.

Szymkowiak, E.J. and Sussex, I.M. 1992. The internal meristem layer (L3) determines floral meristem size and carpel number in tomato periclinal chimeras. Plant Cell 4: 1089-1100.

. 1993. Effect of lateral suppressor on petal initiation in tomato. Plant J. 4: 1-7.

Terry, B.T. and Robards, A.W. 1987. Hydrodynamic radius alone governs the mobility of molecules through plasmodesmata. Planta 171: 145-157.

Tucker, E.B. 1982. Translocation in the staminal hairs of Setcreasea purpurea. I. Study of cell ultrastructure and cell-tocell passage of molecular probes. Protoplasma 113: 193-201.

van Bel, A.J.E. and van Kesteren, W.J.P. 1999. Plasmodesmata: Structure, function, role in cell communication. SpringerVerlag, New York.

Vance, V. and Vaucheret, H. 2001. RNA silencing in plantsDefense and counterdefense. Science 292: 2277-2280.

Waigmann, E., Turner, A., Peart, J., Roberts, K., and Zambryski, P. 1997. Ultrastructural analysis of leaf trichome plasmodesmata reveals major differences from mesophyll plasmodesmata. Planta 203: 75-84.

White, R.G., Badelt, K., Overall, R.L., and Vesk, M. 1994. Actin associated with plasmodesmata. Protoplasma 180: 169-184.

Wolf, S., Deom, C.M., Beachy, R., and Lucas, W.J. 1989. Movement protein of tobacco mosaic virus modifies plasmodesmatal size exclusion limit. Science 246: 377-379.

Xoconostle-Cázares, B., Xiang, Y., Ruiz-Medrano, R., Wang, H.L., Monzer, J., Yoo, B.-C., McFarland, K.C., Franceschi, V.R., and Lucas, W.J. 1999. Plant paralog to viral movement protein that potentiates transport of mRNA into the phloem. Science 283: 94-98.

Zambryski, P. and Crawford, K. 2000. Plasmodesmata: Gatekeepers for cell-to-cell transport of developmental signals in plants. Annu. Rev. Cell Dev. Biol. 16: 393-421. 


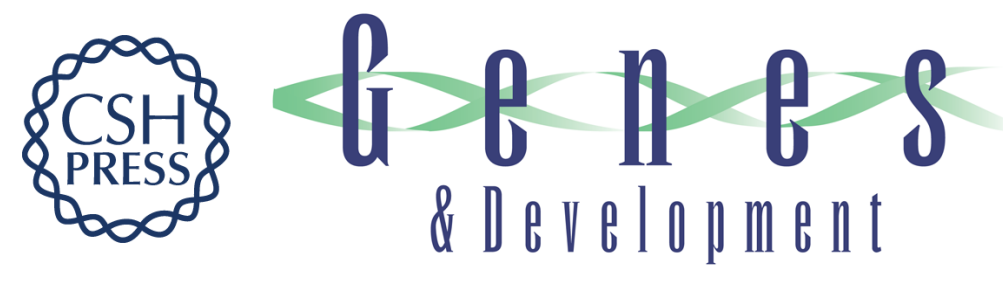

\section{Signaling in plants by intercellular RNA and protein movement}

Xuelin Wu, Detlef Weigel and Philip A. Wigge

Genes Dev. 2002, 16:

Access the most recent version at doi:10.1101/gad.952002

References This article cites 73 articles, 39 of which can be accessed free at: http://genesdev.cshlp.org/content/16/2/151.full.html\#ref-list-1

License

Email Alerting Receive free email alerts when new articles cite this article - sign up in the box at the top Service right corner of the article or click here.

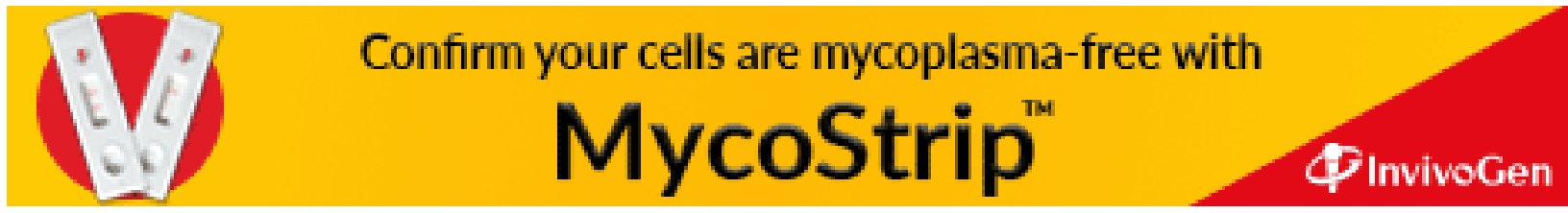

